\title{
Making imagination even more embodied: imagination, constraint and epistemic relevance
}

\author{
Zuzanna Rucińska1] ${ }^{1}$. Shaun Gallagher ${ }^{2,3}$
}

Received: 16 July 2020 / Accepted: 5 April 2021 / Published online: 17 April 2021

(c) The Author(s) 2021

\begin{abstract}
This paper considers the epistemic role that embodiment plays in imagining. We focus on two aspects of embodied cognition understood in its strong sense: explicit motoric processes related to performance, and neuronal processes rooted in bodily and action processes, and describe their role in imagining. The paper argues that these two aspects of strongly embodied cognition can play distinctive and positive roles in constraining imagining, thereby complementing Amy Kind's argument for the epistemic relevance of imagination "under constraints" and Magdalena Balcerak Jackson's argument for justification by imagination.
\end{abstract}

Keywords Imagination $\cdot$ Strong embodiment $\cdot$ Constraint $\cdot$ Performance $\cdot$ Body schema $\cdot$ Epistemic relevance

Once we no longer demand a disembodied (or nonphysical) rationality, then there is no particular reason to exclude embodied imagination from the bounds of reason." (Mark Johnson, 1987, p. 168)

This article belongs to the topical collection on Imagination and its Limits, edited by Amy Kind and Tufan Kiymaz.

\section{Zuzanna Rucińska}

zuzannaaleksandra.rucinska@uantwerpen.be

Shaun Gallagher

s.gallagher@memphis.edu

1 Centre for Philosophical Psychology, University of Antwerp, Rodestraat 14, 2000 Antwerp, Belgium

2 Department of Philosophy, University of Memphis, Memphis, TN 38152, USA

3 School of Liberal Arts, University of Wollongong, Wollongong, Australia 


\section{Introduction}

Imagination is said to be mostly voluntary and under our control. Aside from logical impossibilities and morally deviant worlds (Gendler, 2000, 2010), we seem able to imagine anything we want. Imagining is seen as unconstrained by the environment. It is also often agreed that one cannot get out of imaginings anything more than what one puts into them. However, in recent publications, Amy Kind (2018) and Magdalena Balcerak Jackson (2018) contest these positions in separate ways. They argue that imagination can teach us something new, and can justify our choices, when imagination is constrained by beliefs and wishes (Kind), or due to its recreative nature (being perception-like) (Balcerak Jackson). Beliefs are good kinds of constraints to structure our imaginings since beliefs do not allow "anything goes"- they aim at truth. Perceptions are also good kinds of constraints as they are themselves constrained by facts about the environment.

What has been left out of the discussion is a consideration about the positive role of 'strong embodiment' in constraining imagination. Although there is no consensus on what it means for the mind to be embodied, we follow Alsmith and de Vignemont's (2012) distinction between two broad senses of embodiment: weak embodiment or embodied cognition (EC) and strong embodiment or EC. Weak EC refers to the idea that mental representations of one's body or action goals must be entertained; it "gives a clear explanatory role to representations of the body" (ibid., p. 3). It sees involvement of minimal brain activations in motoric or motoric-related areas as playing an important role in cognition, but conceives of these motoric activations as "body-formatted representations" (Goldman, 2006). Strong EC "depends on the possession and use of a body, not just a brain ... [and] gives a clear explanatory role to the body itself (ibid., p. 3). It refers to the role the extra-neural body plays in cognition-its postures and movements, and the history of bodily interactions that make up a bodily habit, skill or knowhow (see Sect. 3 for detailed discussion). Radical embodied cognitive science has emphasized these stronger, essential roles of embodiment for cognition, and has stepped away from reference to mental or body-formatted representations in its explanatory proposal (Gallagher, 2017; Hutto and Myin, 2013). We aim to further the reach of radical embodied cognitive science and argue for the role of strong EC for imagination.

There has been some discussion about the relation between "weak" notions of EC and imagination. For instance, Neil van Leeuwen (2011) has proposed the Active Imagination Thesis in which imagining involves a continuously updated forward model of action in the world. A forward model is described as "an internal representation of motor commands that anticipates the consequences of those commands on bodily motion" (ibid., p. 56). Likewise, simulationists like Alvin Goldman (2006) suggest that body-formatted representations inform empathic imagination (also see Goldman \& de Vignemont, 2009). On the other hand, proponents of strong EC have mostly posited bodily limitations on our capacity to imagine. For example, in virtue of the way my body is, and my past bodily interactions, imagining what's it like to be someone else is said to be limited 
(Clavel-Vázquez and Clavel Vázquez 2018; see also Sect. 4.3 of this paper). A consideration of strong EC, however, is missing in the discussion about the epistemic role of imagination.

In this paper we look at the role that strong EC could play in the type of arguments put forward by Kind and Balcerak Jackson. Specifically, we'll look at two aspects of strong EC and how they contribute to constraining imagination. We'll argue that it's not only beliefs about bodies, or perceptual simulations, that can play a role in constraining imagination - a view consistent with weak EC - but also that embodiment understood in a stronger sense as including processes related to embodied motoric processes, as well as more explicit processes that involve movement and body-environment coupling, can constrain imagination. In short, this paper will show that embodiment understood in the strong sense is an important addition to the argument that imagination can be epistemically relevant.

The paper will develop as follows. Section 2 discusses the challenge of epistemic relevance as developed in Kind and Balcerak Jackson. Section 3 discusses different senses of strong embodiment and introduces the strongly embodied-enactive imagination thesis. Section 4 then shows how this notion can complement the arguments of Kind and Balcerak Jackson. It also considers the worry expressed by ClavelVázquez and Clavel Vázquez that while body schemas can constrain imagination, the role of these constraints is limiting: one cannot get away from one's own perspective. We'll show how strong EC can deal with this worry, by arguing that movement constrains imagination not in a limiting way, but in an enabling and constructive way. Section 5 follows up on the reach of explicitly embodied imagination and discusses examples of cases when explicit motor processes and movement further enhance imagination, including cases that involve pretend play, training, therapy, learning, and in practices of marking. Such cases show that one can learn something new from a form of imagination that involves movement. Section 6 concludes the paper.

\section{The challenge of epistemic relevance}

\subsection{The 'Up-To-Us Challenge' and imagining under constraints}

In her analysis of the arguments for the epistemic irrelevance of imagination, Amy Kind (2018) distinguishes three distinct claims about imagination: (1) imagination is under our voluntary control, (2) imagining is not world-sensitive, as its content is determined by the imaginer, and (3) imagination is not informative, in that it cannot provide us with new information (pp. 231-232.) Regarding point 1, we do not have control over what we perceive the same way we have control over what we can imagine (we can imagine anytime and anything we want). Point 2 refers to the fact that our imaginings are detached from the environmental constraints, as an act of imagining "typically fails to track changes in the worldly objects with which it is concerned and can diverge dramatically from the actual facts about them" (p. 232). Point 3 refers to Sartre's worry that we cannot get out of an image more than what we put into it. These are in brief the arguments for the epistemic irrelevance of 
imagination. Balcerak Jackson (2018) terms it the Up-To-Us Challenge of imagination: since what we imagine is up to us, how can imagination provide us with justification $?^{1}$ The epistemic relevance and usefulness of imagination is determined by whether we can learn anything from our imaginings, and whether they can justify our choices. These challenges make precise the idea that imagination cannot teach us anything, as suggested by Wittgenstein and Sartre. ${ }^{2}$ Being under voluntary control, imaginings seem to be inadequate epistemic sources.

Is it the case that imagination is so limited, that we cannot learn from it, or justify our choices through imagination? Kind and Balcerak Jackson provide distinct kinds of arguments in response to this view. We'll briefly present these below, and then, following their arguments, we will show how they can be strengthened when we consider them through the lens of strong EC.

\subsection{Imaginings constrained by beliefs}

In discussing a case of extraordinary imaginers like Temple Grandin and Nicola Tesla, Kind (2018) argues against the epistemic irrelevance of imagination. Grandin, for example, famously relied on her powers of visual imagery to design new infrastructure for cattle. Not only did she complete her designs 'in her head', but she also tested the designs using her imagination, similarly to how we run a computer simulation, to check for its flaws and to further improve her designs. ${ }^{3}$ The test-runs gave her complete confidence in the success of her design. According to Kind, this created in Grandin a belief and a trust in her imaginary powers, which served, for her, as justifications for choosing one design over another (ibid., p. 235). Grandin has extraordinary abilities not just to imagine, but to keep her imagination under control.

In response to the question "how is epistemic relevance achieved?", Kind proposes a framework she calls imagining under constraints, and explains how imaginings can be kept under control by reference to constraints. One of the constraints, according to Kind, is a strong desire to not fall prey to "imagining anything one wants", but to strongly desire to "get things right" and to "get at the truth in the

\footnotetext{
1 Balcerak Jackson's 'Up-To-Us Challenge' refers clearly to argument 1 (imagining being under our voluntary control), yet it already encompasses argument 2 (determining of the content), as seen in this quote: "There are at least two plausible senses in which imaginings can be said to be under our voluntary control, or up to us: First, imaginings are mental states that we do not passively endure, but that we intentionally engage in when we choose to do so. And second, imaginings are mental states whose content is determined by what we choose to imagine" (2018, p. 212).

2 In Zettel, Ludwig Wittgenstein writes: "Imaginings tell us nothing about the external world ... Imaginings are subject to the will ... It is just because forming an imagining is a voluntary activity that it does not instruct us about the external world" (1981, §632). And in The Psychology of the Imagination, JeanPaul Sartre states: "The image teaches us nothing ... No matter how long I look at an image, I shall never find anything in it but what I put there" (1972, p. 7). See also Balcerak Jackson 2018, p. 212.

3 As Grandin (1995) writes, "Visual thinking has enabled me to build entire systems in my imagination... Now, in my work, before I attempt any construction, I test-run the equipment in my imagination. I visualize my designs being used in every possible situation, with different sizes and breeds of cattle and in different weather conditions. Doing this enables me to correct mistakes prior to construction" (pp. 19-20; see also Kind 2018, p. 234).
} 
imagining" (ibid., p. 241). In short, it is the will, aim, or desire of the imaginer that can influence whether the imagining is correct or appropriate. For example, we can consider situations where the stakes are high to imagine correctly (such as when strategizing about how to win a competition), and in such situations, the desire of the imaginer to imagine correctly will act as a relevant constraint for the imaginings. We can call this "the strong-willed imaginer" case.

However, it is not clear that everyone can be such a strong-willed imaginer. A pressing question is whether simply willing the imagining to be aimed at truth in fact lets us achieve this. Can we trust our strong will to imagine correctly? Kind (2018, p. 244) recognizes a similar worry, when she writes:

I might not always be good at setting the right constraints, and I might not always be good at abiding by the constraints that have been set. (...) I might embellish [my imaginings]. But when I do set the right constraints, and when I am good at abiding by them, my imagining can be as epistemically relevant to my project as [Grandin and Tesla's] imaginings are to theirs.

There is something else that is necessary to help us constrain our imaginings. Kind suggests that this something is belief. Kind thinks that it is a mistake to think that imaginings must be completely world-insensitive; how they get to be worldsensitive is when beliefs (about the world) infuse imaginings. Supposing we can all be strong-willed imaginers, we also need to be accurate believers, as the various beliefs about the world we have "infuse (our) imaginings", and act as constraints on imagination "just as pre-programmed variables set constraints on computer simulations" (ibid., p. 243). Let's take a look at another example from Kind's earlier work (2016, pp. 155-156):

A prospective parent-call her Imogen-might engage in various imaginings in an effort to figure out whether she is ready to have children, or what kind of car to buy, or where to put the crib. If she wants these imaginings to be epistemically useful to her, it seems natural that she will deliberately attempt to line them up with her conception of the world. These aren't mere daydreams, but rather are controlled-that is, constrained-imaginings. For example, when she imagines the crib against the various walls of the room that will become the nursery, her imagining is constrained by the actual size of the room [emphasis in original], the actual size of the crib, the placement of the windows and doors in the room, and so on. Will the door still comfortably open if the crib is placed against the west wall? This can best be determined if both the reality and the change constraints are met-if she imagines the room as it actually is [emphasis added], but suitably adjusted for the insertion of the crib.

But how do we know if the beliefs constraining our imaginings are aimed at the truth, and have not been compromised? Beliefs, after all, are fallible, and prone to misrepresentation. Also, how can we make sure that the imagining is of the world as 
it actually is? How can the world (the actual size of the room or the crib) constrain Imogen's imagining, even if her beliefs about the world are accurate? ${ }^{4}$ How do we know if the link between her imagining and her beliefs is intact? As Imogen's imaginings are not done in the respective environments, it is not the relevant environment itself, but how this environment is represented, that constrains her imaginings.

To paraphrase Daniel Hutto (2015), the root problem is that "what is imagined is rarely, if ever, present and causing such imaginings in the right kind of way" (p. 76). If imaginings are guided by beliefs which strive to tell us how things presently stand with the world, then they could easily misrepresent the world, because the imagining is never done in the presence of what is imagined. We can easily misrepresent or misremember the room (Kind acknowledges this problem by naming it the 'imaginative illusion'), or engage in wishful thinking (imagining the room as bigger than what is remembered), in order to match the desire to fit the crib into the room. Similarly, desires can have a distorting influence on our imaginings. For example, we can have a more favorable body image of ourselves than the body we have in reality. We might embellish what we imagine, as Kind acknowledges. Kind does not propose an alternative to these worries other than a capacity to set for oneself the right constraints and abide by them, as the above quote showed. However, we challenge whether such 'strong will' alone is sufficient to keep the link between one's beliefs and one's imaginings intact.

In this regard we will provide an alternative to thinking of this simply in terms of desires and representations. According to our version of the strong EC of imagination, the world (the actual size of the room or the crib) can constrain Imogen's imagining in the right way because moving in the relevant environment has directly shaped our imaginative projections. We will elaborate on this view in sections below.

\subsection{Imaginings constrained by perceptions}

Balcerak Jackson's (2018) response to the 'Up to Us Challenge' does not consider beliefs or desires, but focuses on the mere fact that imagination is recreative. She argues that imagination, "thought of as a recreative capacity that stands in a close relationship to our perceptual capacities, provides us with information about experiential possibilities" (ibid., p. 210). She proposes that there is a "tight relationship between imaginings and perceptual experiences" (p. 220), as perceptual experiences provide us with "evidence about which objects there are in our immediate external environment ... [as well as with] evidence about how things look to us, whether or not things in our external environment actually are the way they look" (ibid). Since perception is taken to be a paradigmatic source of justification for our everyday beliefs, Balcerak Jackson writes that imagination provides justification "in virtue of

\footnotetext{
4 There are two subtly different issues in play here: the issue of whether the imagining in question is constrained by "good" beliefs, and the issue of whether the link between one's (supposedly good) beliefs and one's imagining is suitably intact. We would like to thank the anonymous reviewer for this clarification.
} 
being a recreativist or simulationist cognitive capacity" (p. 216) and "in virtue of being by their very nature derived from or parasitic on perceptual experience" (p. 221). As she says, "because imagination is constitutively a capacity to recreate perceptual experiences - in Yablo's words, an ability to run the perceptual faculty 'offline' - it can tell us how things look" (pp. 221-222).

How does this move provide explanation of the justificatory role of imagination? According to Balcerak Jackson, what provides justification for our choices are perceptual experiences, because they are outside of our voluntary control, and "the contents of those experiences are determined by causal or functional relations to properties instantiated in it" (p. 213).

But in what sense are imaginings really like perceptions? Consider the thoughtexperiment of Peter Langland-Hassan (2015). Joe wants buy a new couch. He imagines a new couch to fit through the front door. However, when the couch arrives, it does not fit. As Langland-Hassan summarizes, "The imagining was a failure. Our conception of its correctness conditions should reflect that fact" (2015, p. 672). One explanation for this possibility of failure is that the imagining was not systematically fixed by the environment. If imaginings are guided by contents of perceptions which strive to tell us how things presently stand with the world, then, as with the case of beliefs, they could easily misrepresent the world, because, in contrast to perception, they are also not systematically fixed by and coupled to the environment. Balcerak Jackson seems to anticipate this move, and acknowledges that the occurrence and the content of imaginings is "not systematically fixed by the external environment" as are perceptual experiences (p. 214). Her proposal, however, is that "Imaginings justify us in beliefs about ways things could look because they are relevantly similar to experiences that could have been had (emphasis added)" (p. 221).

This possibility, however, can lead to imaginings that are too open, and therefore, always correct. If imaginings simulate perceptions and represent various scenarios about the world not as is, but as being possible (à la Yablo, 1993), "then the correctness conditions for sensory imaginings are so unconstrained that they turn out to be almost always successful" (Hutto, 2015, p. 76). In that case, imaginings would end up not having the same constraints as perceptions do, but be much more open. Therefore, the mere fact of being a recreative capacity may not be a feature of imagination sufficient to play constraining and justificatory roles. ${ }^{5}$ Also, Balcerak Jackson's argument is that recreative imaginings are sufficiently perception-like because they give us similar experiences to those that "could have been had", and therefore, they justify our choices. But this view has its limitations. For how do you get from knowledge about appearances (of how things could look or could be), to knowledge about how things are $?^{6}$ Balcerak Jackson does not provide an answer to this question. Knowledge about how things are is the kind of knowledge that is available from perception.

\footnotetext{
5 Unless one accepts that justifications regarding what is possible form modal knowledge that still plays a significant epistemic role. Thanks to the anonymous reviewer for this point.

6 Thanks to the anonymous reviewer for this point.
} 
Our proposal is that imaginings can be recreative of perceptions, not because they simulate possibilities for action 'as possible', but because in imagination, we re-use the perceptual motor system in the act of prospecting future actions (see also Gallagher \& Rucińska, 2021). Our model provides a reason to think that in imagination we get to reenact what was actually perceived, which better justifies our choices made on imagining scenarios. We will elaborate on our proposal in the sections below.

To summarize, we should ask what further constraints my beliefs must have for them to constrain my imaginings in the right way (to enhance Kind's argument), and what further is necessary to give my imaginings a justificatory role beyond its capacity to represent possible scenarios (to enhance Balcerak Jackson's argument). Both questions can be answered by turning to a strong sense of embodied cognition, which involves sensorimotor contingencies, body-schematic processes and active movement, all of which provide the right kinds of constraints on imaginings. We will argue that the strongly embodied imagination thesis presented below is not incompatible with 'constraining-via-belief-and-desire' and 'constraining-by-being-perception-like' views; on the contrary, we will show that it can substantially strengthen the proposals of Kind and Balcerak Jackson. The next section will discuss different senses of embodied cognition and show how embodiment complements the arguments of Kind and Balcerak Jackson. We will then provide the response to the "UpTo-Us Challenge" from the perspective of embodied and enactive cognitive science.

\section{Different views of embodied cognition and imagination}

\subsection{Multiple senses of embodiment, including weak EC and strong EC}

There are multiple senses of "embodiment" and embodied cognition in the philosophical and cognitive science literature. For example, Di Paolo and Thompson $(2014$, p. 68) capture the variety of distinctions that the term "embodied" has referred to in this context, including

anything from conservative ideas about how bodily action provides a format for neuronal representations (Goldman and de Vignemont, 2009; Gallese, 2010; Goldman, 2012) or helps to reduce computational load (Clark, 2008; Wheeler, 2005, 2010; Wilson, 2004), to a variety of "radical embodiment" (Clark, 1999; Thompson and Varela, 2001) proposals-for example, that kinesthetic body schemas are a constitutive part of mental skills (Lakoff and Johnson, 1999; Núñez, 2010), that sensorimotor know-how is a constitutive part of perceptual experience (O'Regan and Noë, 2001; Noë, 2004), that bodily life regulation is a constitutive part of phenomenal consciousness and its extended neurophysiological substrates (Thompson and Varela, 2001; Thompson and Cosmelli, 2011), and that social sensorimotor interaction can be a constitutive part of social cognition (De Jaegher et al., 2010).

In effect there are multiple things that the concept of embodied cognition might reference, including the notions of the body image and body schema (e.g., Gallagher 
\& Cole, 1995), body or B-formatted representations (Goldman \& de Vignemont, 2009), motor activation and implicit motor control processes (Rowlands, 2006), bodily habit or a form of know-how (Silverman, 2017), sensorimotor contingencies tied to movement (Noë, 2004), affectivity (Colombetti, 2014), or the role of embodiment in social cognition, interaction and joint action (Gallagher, 2020). This list, which is not exhaustive, simply reflects some of the concepts and factors associated with embodied cognition in the literature. Some of these concepts can be interpreted as closely related to one another (e.g., body schemas are related to bodily skills), or as entailing one another (e.g., body schema, on the reading of Goldman and de Vignemont, can be reduced to a "B-format" as "a 'sanitized' way of talking about the body, and 'the most promising way' to promote" embodied cognition (2009, p. 155; see also Gallagher, 2017). Some senses of embodiment have also been seen as trivial, as, for example, the idea that embodiment includes neuronal activation, or that it involves a historical role of the body (Shapiro, 2011). As these concepts come from different traditions (analytic philosophy of mind, phenomenology, psychology, neuroscience), they have often been analyzed separately, and divided up in different ways.

For our purposes we'll adopt a general distinction that has been accepted by proponents of EC in different camps. This is the distinction between weak and strong $\mathrm{EC}$, which is more nuanced than it first might appear. As explained in the introduction, weak EC takes B-formats and motor-related neural simulations to be explanatory for certain types of cognition. Goldman and de Vignemont (2009), for example, provide a neurocentric account in which they make it clear that B-formats, rather than the body itself, or anything like body-environmental coupling, are what do the real work in cognitive processing. In contrast, strong EC contends that the body itself (including morphological, motoric, and affective features) and the processes of attunement that couple the body to the environment, contribute to, and sometimes constitute, cognitive processes. Strong EC, of course, does not rule out the important role of brain processes, but provides an alternative (non-representational) view of how the brain actually functions.

Accordingly, we need to introduce some clarifications to address an ambiguous conceptual space where weak EC and strong EC seem to overlap, specifically with respect to neuronal processes. ${ }^{7}$ On one view this overlap might signal a kind of continuity between weak EC and strong EC. On an alternative view there is an important difference that derives from the fact that these approaches have different starting

\footnotetext{
7 Thanks to an anonymous reviewer for raising this issue. The ambiguous area of overlap has been noted by Alsmith and de Vignemont (2012, p. 4), who mention the following example: "Equivocation in this regard is easily invited by the use of ambiguous terms like 'body schema'... In the mainstream neuroscientific usage, the term 'body schema' typically refers to an internal representational process of integrating sensorimotor information to enable holistic motor control ... implicating weak embodiment at most ..." In contrast, a phenomenologically inspired use of the term "refers to a strongly embodied sensorimotor process, strongly embodied in so far as it is clearly intended to include peripheral sensory organs and effectors in the channeling and structuring of information flow (Gallagher, 2005a; b). This is a clear instance in which the contrast between strong embodiment and body representation presents a real tension."
} 
points and, so to speak, come at the issues from different directions. Weak EC starts with a more standard or classic cognitivist position that defends the idea that there are different representational formats that include propositional and non-propositional formats. B-formats and neural simulations are non-propositional in format, but continuous with the computational-representational framework of classic cognitivism. Goldman and de Vignemont (2009), for example, suggest that social cognition involves a range of processes where propositional representations do much of the work but may be supplemented by B-formats or simulations in the mirror neural system. B-formats, which may involve neural activation in motor areas, are conceived of as, in some sense, continuous with or complementary to propositional representations of the classical sort, but they are viewed as discontinuous or decoupled from actual bodily processes (Alsmith \& de Vignemont, 2012). In contrast, these same neural activations referenced by weak EC receive a different interpretation in what is sometimes called a more 'radical' perspective of strong EC. Strong EC starts with the idea that the body itself-including, for example, its sensory, affective, and autonomic processes, its way of coupling with and moving through the environment-constitutively contributes to cognitive processes. Bodily factors shape the way the brain works (phylogenetically, ontogenetically, and in the ongoing processes of everyday cognition). Brain processes, on this interpretation, are 'rooted' 8 in bodily processes. In social cognition, for example, mirror neuron activation is not viewed as a backward-facing internal representation or simulation of what the other person has just done, but as part of an enactive response that primes the perceiver's body for her interaction with the other (Gallagher, 2020, pp. 117-118). Such processes are not discontinuous or decoupled from bodily action, they are processes of the body-in-action. ${ }^{9}$

In this paper we won't have the opportunity to resolve or even try to address all of these issues, including ongoing debates about the role of representation in cognitive science. In our discussions of rooted brain-body processes, however, we plant our flag in the strong EC camp. Thus, in the following we distinguish between concepts related to weak EC, and two sets of strong EC concepts, namely, those related to rooted bodily processes and explicit motor processes. For the purposes of this paper, we focus on the latter two kinds of processes, which fall under the idea of strong EC, because they involve the body in shaping and maintaining cognitive processes in a way that cannot be uncoupled from the environment, in contrast to the paradigmatic cases of body representations that are strictly internal and uncoupled.

\footnotetext{
${ }^{8}$ We mean the term 'rooted' to directly reflect the original meaning of 'radical', as in radical embodied or enactive cognition. We propose to introduce the term 'rooted cognition' in order to distinguish it from what is sometimes called 'grounded' cognition used in weak EC accounts.

${ }^{9}$ Alsmith and de Vignemont (2012) review some debates about action-oriented processes in forward models involving motor control, where on a weak EC interpretation such processes are said to involve minimal (B-) representations that function offline, decoupled from body and environment (e.g., Clark \& Grush, 1999; Wheeler, 2005). On a strong EC interpretation these same forward processes are part of the online motor control processes that are directly tied to bodily movement and cannot be decoupled from current bodily posture or environmental structure (e.g., Gallagher, 2008). To the extent that these motor control processes can be cashed out in neural terms, these are clearly different interpretations of the same neural processes.
} 


\subsection{Rooted bodily processes and their role in imagination}

Rooted bodily processes include implicit body-schematic and sensorimotor processes, which involve both neural and extra-neural processes. They are shaped by the history of bodily interactions as they contribute to habit formation and skill, as well as situated and affective factors. Such processes typically operate in occurrent action, but they are also active when we are not engaged in action. ${ }^{10}$ These rooted processes do not require occurrent explicit movement or need to be visible in action, which is what the explicit embodiment category aims at capturing, yet they have important, permeating effects on cognition.

In our view, the body schema is best understood as a system of sensory-motor processes responsible for the regulation of bodily posture and movement, following the phenomenologically inspired use of the term (Gallagher, 2005b; see also Alsmith \& de Vignemont, 2012). ${ }^{11}$ The body schema can be defined as a system of preconscious, subpersonal, sensorimotor processes that play a dynamic role in governing and regulating bodily posture and movement. Body schemas define possibilities of bodily movement and play a significant role in motor control and in instantiating skills (e.g., Kim, 2020). Specifically, on affordance-based enactive interpretations, body-schematic processes constrain perception by defining possible actions in specific environments. They can also influence judgment and decision making (Petracca, 2020) and more abstractly, they are said to inform "image-schemas" that underlie metaphor use and abstract conceptual thought (Lakoff \& Johnson, 1980). Hence, they function as rooted bodily processes.

Body-schematic processes include sensorimotor contingencies, or a kind of sensorimotor know-how that plays a role in bodily engagement for cognition. The sensorimotor view relates to rooted processes when it refers to facts about the body and the way the body is, such as the structure of our visual systems, which in turn define our possible perceptions and movements. O'Regan and Noë (2001, p. 1013) state that "differences in our bodies (and thus in sensorimotor contingencies) will make a difference to our experiential states", and "a crucial fact about vision is that visual exploration obeys certain laws of sensorimotor contingency. These laws are determined by the fact that the exploration is being done by the visual apparatus" (ibid, p. 941).

How are rooted bodily processes present in imagination? Consider again Kind's example of imagining where to place the crib. On an enactivist view, we don't simply imagine the west wall and the objective placement of windows and doorways in

\footnotetext{
${ }^{10}$ See Kyselo and Di Paolo (2009) for a discussion of the role of body-schema and sensorimotor activation in patients with Locked-In Syndrome (LIS).

${ }^{11}$ It is possible to think of body schemas as mental representations of bodily behaviors"representations of the body as a structure made of parts connected by joints" (e.g., Hochstetter, 2016; Longo \& Haggard, 2010; de Vignemont, 2010), just as it is possible to interpret sensorimotor contingencies as mental representations. Such an interpretation tends to ignore the roles of the peripheral nervous system and the environment. It turns strong embodied-cognitive processes into weak embodied cognition and reduces full-bodied processes to B-formats in the brain. For arguments against this type of reductionism, see Gallagher (2015).
} 
an abstract geometry. More likely we imagine how we might move around the room if the crib was there, or how we could reach to open the window with the crib placed on that wall. This imagining is enacted because it makes use of reenacted perceptions and sensorimotor schemas, as shaped by the way our body is and how we are able to move, to reach, to lift, etc. If, in contrast, we were disabled, and operated with a different set of sensory-motor contingencies, our imagined room arrangement might be somewhat different. In addition, imagining can be guided or constrained by affective processes. Affectivity may play some significant part in our imaginings if we are not simply imagining the way a contracted engineer might imagine furniture placement. Imogen, as a prospective parent, is likely feeling something - joy, nervousness, uncertainty, pressed for time, etc. - as she is attempting to imagine the nursery, and whatever the embodied-affective mix is, it likely affects what and how she imagines things will be.

What I am imagining, however, doesn't have to feature my body in any explicit way. For example, in imagining a bright-white snowy mountain top with eagles flying high over the tops of tall oaks and the wind blowing from the side, what I imagine does not include my body as part of the content, yet what I imagine will be defined by my bodily possibilities (what sorts of movements I can make and the kinesthetic sensations that may accompany those movements) and perhaps specific past bodily movements (for example, the fact that I can look up, and have moved my head to look up when I have previously encountered mountains). It is also constrained by an egocentric (i.e., body-centric) perspective-my imagining of the mountain entails that I am imagining it from a position that would be occupied by my body (for example, the wind will be blowing from left or right, which involves an implicit reference to an egocentric spatial frame of reference centered at my body) - and by activation of affective processes in the body. If I am refreshed in the morning or in an extremely good mood, I may imagine the mountain as climbable; if I am fatigued, however, I imagine it as less climbable (Gallagher \& Bower, 2014).

What I am visualizing does not have to involve representations of what has been seen either. Consider Ilundáin-Agurruza's view of visualizations, that contrasts with the weak EC proposals, which think of them as implicit and representational processes. For example, he discusses the case of the famous free soloist Alex Honnold, who recounts how before his first solo climb of Moonlight Buttress's sandstone wall, he spent the prior two rainy days "sitting and thinking, hour after hour. Visualizing every single move, everything that could possibly happen (...), every handhold and foothold on the long way to the top of the wall" (Ilundáin-Agurruza, 2017, p. 100). Ilundáin-Agurruza stresses the fact that even such visualizations are preceded by corporeal imaginings. Corporeal imaginings are densely textured in a cross-modal way, and involve re-enactments of perceptual activities based on both past and present material and bodily engagements. Ilundáin-Agurruza contrasts corporeal imaginings with eidetic imaginings, which are concerned with absent situations, and which unfold when visualizations are "beholden to propositional content" (ibid., p. 97). As he explains, "Even in Honnold's exhaustive visualization, generative [corporeal imaginings] precede representational [eidetic imaginings], whether these be fanciful dreams or goals of veridical imagined possibilities. (...) [One reason is that] such exacting visualizations are not merely pictorial. Surely, they are 
visually complex, but more importantly, they are densely textured in a cross-modal way: kinetic, tactile, kinesthetic, nociceptive, even olfactory and gustatory dynamics are pertinent. These are acquired and felt in the midst of performance" (ibid., p. 101; also see Mitchell, 2016). Hence, on this view, visualizations involve processes seen as rooted in bodily processes. While visualization need not engage explicit movement, it can still be thought of as an explicitly embodied process.

Thus, embodiment in the strong sense shapes or structures not only how I imagine, but certain aspects of what I imagine as well, even if the body-as-content is not a necessary feature of embodied imagining. We will discuss below some examples of embodied imagination that are clearly influenced by these rooted processes in the context of their epistemic relevance.

\subsection{Explicit bodily processes and their role in embodied/enactive imagination}

In contrast to rooted motoric processes, explicit bodily processes entail active movement, performances, and occurring bodily interactions. Let's consider perception and action first. O'Regan and Noë (2001) propose that the active moving body anchors perceptual experience, and so refers to explicit motor processes. Cognition "is not something that happens in us", but "something that we do ... in our dynamic living activities" (Noë, 2004, p. 64) and it involves "the active engagement the perceiver undertakes with the environment" (O’Regan \& Noë, 2001, p. 962). Kyselo and Di Paolo (2015, p. 523) suggest that this "active engagement in an ongoing coupling with the world ... is the process by which mastery of the laws of sensorimotor contingencies can take place." Such rooted sensorimotor contingencies are re-shaped and mastered through explicit movement and ongoing engagement with the world. Movement creates new sensorimotor experiences and informs body-schematic processes. According to Noë (2004), one is able to feel the shape of a specific object's surface by "active touching (probing, prodding, stroking, rubbing, squeezing) with your hands", but the "tactile impression" does not only rely on "sensations in your hands and feet" but on their "movement through space" (p. 15). Explicit movement thus forms an important factor in the role of past experience and the history of bodily interactions, which further shape our embodied habits and skills.

If all of this is on the right track, what role does movement itself play for imagination?

Explicit embodied/enacted imagination is a proposal that focuses on imagining as bodily doing. Analogous to perception and other forms of cognition, imagination, according to enactivist approaches, is something that we do, not something that merely happens to us. For instance, José Medina (2013), building on Hutto's (2010) notion of enactive imagination, and drawing on evidence involving oculomotor activity during visual imagination, speaks of imagination as re-enactment. "[I] magining is not something that happens to us, it is something we do, something that requires active participation, a form of action and interaction" (Medina, 2013, p. 319). Imagining can be integrated with perception and action in an ongoing dynamical pattern; it is a construction that involves motoric processes, which are habitually informed by perception; it is thereby not reducible to simply having an image 
in one's head. Medina gives an example of visually imagining a room, which he characterizes as "enacting or re-enacting seeing that room, moving our eyes around it and checking things out, and not simply seeing a picture-like mental image of the room with our mind's eye, or having a mental model of it" (p. 319). This is even clearer if we are actually in the room imagining how we might arrange the furniture. Moving around, gesturing here and there, and so forth, would clearly support our imaginings of placing the furniture that is not yet there. Just as visual imagination involves a re-enactment of seeing, "other forms of imagining are likely to involve other forms of enactments: for example, enacting touching or being touched, enacting speaking or listening, or enacting specific movements such as grasping, holding or releasing through the activation of the sensorimotor patterns involved in the preparation of those actions" (p. 320).

The 'moving body' contributes to the process of imagining, as a means for imagining new possibilities. Such imagining is not uncoupled from acting on the environment. Explicitly embodied imagination goes beyond the dichotomy between 'creative' and 'recreative' imagination, as proposed by Currie and Ravenscroft (2002). According to them, recreative imaginings involve 'body representations': the body features as the content of the imagining, and the imagining has contents that are "like" those of experienced movement. ${ }^{12}$ On the enactivist reading, recreative imagination involves perceptual re-enactments of our experiences and routines (Hutto, 2015). Creative imagination, on the other hand, is when someone "puts together ideas in a way that defies expectation or convention" (Currie \& Ravenscroft, 2002, p. 9). Currie and Ravenscroft interpret this as a generative capacity, which involves putting new ideas together, a capacity that is thought to be hypothetical and disembodied. An alternative interpretation of creative imagination involves a body in action featured in the creative process. Explicitly embodied imagination captures just this alternative: active movement brings forth new imaginative experience and can participate in creative imagining.

To flesh this out, let's consider some examples of how explicit bodily processes can enhance imaginative experiences. The first example returns to rock climbing and the practice of marking. According to Sanchez-Garcia et al. (2019), saying that expert climbers benefit most from route preview by visually inspecting a climb does not capture what it is that the climbers are doing in practice, which often involve, before actually climbing the wall, miming the movements they will perform. What is particularly interesting about the visualizing process amongst climbers is that is explicitly embodied: it is often coupled with explicit gesturing done right before the climb. This is the practice of marking - an exploratory set of gestural movements that rehearse the actual climb (a practice also used by dancers [see, e.g., Gallagher, 2021]). Climbers engage in explicit marking to visualize how the climbing sequence

\footnotetext{
12 "Imaginative projection involves the capacity to have, and in good measure to control the having of, states that are not perceptions of beliefs or decisions or experiences of movements of one's body, but which are in various ways like those states-like them in ways that enable the states possessed through imagination to mimic and, relative to certain purposes, to substitute for perceptions, beliefs, decisions, and experiences of movement. These are what we are calling states of recreative imagination" (Currie \& Ravenscroft, 2002, p. 11).
} 
should unfold (Rucińska, 2021). Marking is a visible and public process of "corporeal enacting of the actual movements as if they were already engaged with the material effort of vertically progressing up the wall" (Sanchez-Garcia et al., 2019, p. 519). In marking, we are imagining through our gestures. For instance, to imagine a climb using marking is to run through a sequence of movements to map out the upcoming climb. This movement allows for better visualization of one's bodily position to be taken during the climb. Interestingly, marking is often done together with other climbers, which means that it can be constrained by others as well. When engaging in marking, the climbers look at the wall together and discuss it with each other. This even takes place at climbing championships, during which collective observation period is allowed (Rucińska, 2021). This behavior is "not an isolated, subjective, and individual activity: it is a social and shared chain of anticipatory actions" (Sanchez-Garcia et al., 2019, p. 519), which results in "a kind of dynamic bodily configuration, a sort of synchronized dance, a shared choreography of steps, which are jointly performed and practically displayed" (ibid., p. 520). The sociallyobservable sequence of public marking suggests that the imagining can also be an intersubjective activity.

A second example involves teaching a self-defense class. In this context the trainer, through her own bodily positions, paints a picture of how to physically defend oneself from an attacker. The trainer alternates taking on the position of the attacker and the victim and enacts, in a safe space, different techniques and courses of actions and events that can follow in a situation of an attack. Enacting such movements can also be interpreted as a form of marking — with one's body — where the attacker is and where the victim is, and how to proceed. Not only is this a process of imagining enacted through movement by the teacher, but, according to Stuckenbrock (2017), such training "invites the [students] to not only watch, but to mobilize their embodied imagination to join in, to co-participate in the emerging interchange between victim and aggressor" (p. 245). The students can also "be observed to verbally and bodily interact with their constructs as if they were there, coordinating to and with them (...) and thereby constituting an intercorporeal relationship with those phantom phenomena" (ibid., p. 240). Stuckenbrock terms this phenomenon joint imagination:

Joint imagination is not conceptualized in a mentalistic way as a purely cognitive operation requiring a third person model to be constructed in imagination and projected upon the imagined scenario, but as an experiential, embodied process of joint imagination and (con)joint displacement. ... (J)oint imagination occurs when participants interactively establish co-orientation to imagined phenomena." (ibid., p. 239)

In joint imagination, the imagining is shared and dynamic. According to Stuckenbrock, the participants "do not permanently remain in the imagined situation. Instead, they rebuild it again and again, they interrupt it, transform it, step in and out of it to reflect on how they are doing what they are doing and what they have been experiencing. Thus, they continuously shift between the imagined intercorporeal domain and the immediate intercorporeal reality of the here-and-now in the gym" (2017, p. 242). Joint imagining is dynamic and informative; it's something we 
can learn from. Marking and joint imagination also show that strongly embodied imagination allows for a situation whereby others can form the constraints for our imaginings.

\section{What follows about the epistemic relevance of imagination from strong embodied cognition?}

Does strong EC make a difference for the epistemic relevance of imagination? So far we have said what strongly embodied imagination looks like. But how does strong embodiment, including its two aspects, rooted bodily processes, and explicit movements, constrain the imaginings? In this section we will refer back to Kind and Balcerak Jackson's positions, focusing first on rooted processes. We will show how the way to interpret cognitive and perceptual processes as rooted in embodiment (following strong EC, and not just grounded in body representations as per weak EC), make a difference to how strongly their arguments can justify imagination as epistemically relevant. Then, in Sect. 5, we will discuss the added value of explicit movement for the epistemic relevance of imagination. But first, we'll say something about a weak version of embodied imagination not discussed above, the 'body-ascontent' view of weak EC.

\subsection{The 'body as content' view}

One weak way to understand imagination as embodied is to say that one entertains imaginings of the body. Embodied imagination sometimes refers to an imagining that involves mental imagery of one's body or entertaining a proposition about one's body. For example, Currie and Ravenscroft speak of embodied imagination when motor images "have as their contents active movements of one's body" (2002, p. 88). This proposal, however, doesn't bring anything interesting to the debate on the limits of imagination. Reducing the role of the body to being a contentful state will play the same role as beliefs in the constraining of imagination (Kind, 2018). Those beliefs will simply be about bodies, and such contents will not by themselves further constrain the beliefs.

Consider again visualizing for rock climbing. Before engaging in climbing a wall, rock climbers engage in the process of visualizing how they will climb. One way to interpret why the acts of imagining their pending climbing actions are successful is to say that their imaginings are constrained by their beliefs about their bodily capacities. These beliefs determine their conscious awareness of how far their arms can reach, and what movements they can do. Climbers can accurately imagine their climb by forming accurate contents of their beliefs about their climbing capacities, and allowing those beliefs to permeate their imagining of the pending climb. For example, believing that his arms are short, Alex' belief infuses his imagining of not 
being able to reach the next hold of the rock, and so makes Alex choose to jump in order to reach that hold. ${ }^{13}$

A problem with treating this weak conception of embodiment which targets the body-as-content as constraining imaginings concerns misrepresentation. Alex's beliefs about his body could be wrong. It is possible that in forming a system of beliefs or attitudes about the body, the system can involve inconsistency or contradictions. We could falsely believe in one's strength, and embellish one's body image (e.g., believing that we are taller or more flexible than we really are) and our desire to "get things right" might not be enough if we depend on such false beliefs about our bodies. Thus, something other than contents need to constrain that belief or desire.

In our view, body schemas can further constrain beliefs about our capacities, and control our imaginings so as to avoid inconsistencies. Recall that body schemas are not internal representational states, but sensory-motor processes responsible for the regulation of bodily posture and movement (Gallagher, 2005b). Body schemas therefore are neither belief-like, nor involve processes that have truth conditions. In this regard, body schemas do not face the worry of inconsistency or contradiction, or being embellished, as they are not truth-tracking representations of our bodies, where misrepresentations can occur. We will discuss the role of thus-conceptualized body schemas for epistemic relevance below.

\subsection{The epistemic relevance of rooted bodily processes}

One way to understand how rooted embodiment constrains imagination is to base beliefs and perceptions relevant for imagination in rooted bodily processes. We will hereby show that conceptualizing beliefs and perceptions as rooted bodily processes, just as imaginings, and not as implicit representational processes, can enrich both Kind and Balcerak Jackson's proposals about the justificatory role of beliefs/desires and perception for imagination.

Kind, as we summarized, argues that imaginings can gain epistemic value if they are under constraints, but those constraints are beliefs. Even though such beliefs could easily involve beliefs about the body (body-as-content), what makes a difference in structuring the imagining is for those beliefs to stem from rooted embodiment. Beliefs (also desires and intentions) that constrain imagination can be embodied in a relevantly strong sense, constrained by our bodily schemas, inseparable from and found within embodied activity, and emerging through interacting and engaging with the world over time (see Hutto, 2015, p. 83). Through the lens of body schematic processes, for example, we can re-consider Temple Grandin's case: she is successful at constraining her imaginings not just because she is a strong-willed imaginer or entertains, luckily, correct beliefs about the world, but because her past body-schematic and her present motor capabilities actively guide her imaginings; her mental imagery involves actively drawing on her motoric habits and skills.

\footnotetext{
13 As we've seen in the case of marking, however, this is not the only way to understand why visualizing works for climbers.
} 
Thus, while Kind writes that beliefs about the world infuse one's imaginings, arguably, body-schematic processes first infuse beliefs about one's action capacities and possible pragmatic engagements with the world, as well as one's desires. In addition, affective components of rooted embodiment can shape one's dispositions to embellish (if, for example, one is in an overly optimistic mood), or to think of the world accurately. Our rooted embodiment might even influence which limitations on imagination we think of as logical impossibilities, even though they actually stem from anatomical or physiological functions. ${ }^{14}$

Another way to understand how rooted embodiment constrains imagination is to reconsider what beliefs and desires are. One can follow Langland-Hassan's (2020) 'light duty ontology', according to which someone who believes or desires that $p$ has certain characteristic dispositions to behavior. Beliefs and desires understood as dispositions for actions do not entail truth-evaluable contents, and so, are already in line with the non-representational notion of the body schema. Also, dispositions to act in certain ways are shaped by and rooted in sensorimotor experiences. Hence, if beliefs and desires are dispositions for action, then they will be shaped by strong embodiment as well.

Finally, environments in which we do the imagining will shape the way that we imagine, because they are not mediated by fallible representational processes. From our perspective, the past engagement with the crib can constrain Imogen's imaginings related to the placement in the baby room in a direct way, because the motoric processes involved in perceiving and studying the crib are reenacted in the imaginative projections.

With regard to the justificatory role of imagination as parasitic on perception, Balcerak Jackson argued that imaginings can justify because they involve perceptual simulations of possibilities for action, represented 'as possible'. We agree with Balcerak Jackson that imagination is parasitic on perception, but we propose to reconsider perception as sensorimotor and rooted in embodiment. We follow the enactivists and think that perceptual states are achieved through sensorimotor processes and moving in the world (O'Regan \& Noë, 2001). Hence, if imagination is indeed parasitic on perception, and if imagination involves reusing perceptual and motoric systems that are tightly coupled to action (so instead of imagination being recreative, it is sensorimotor), then the contents of imaginative states will also be rooted in perceptual and motor systems. While involvement of motor systems may also be a sufficient condition for weak EC simulationists, the difference in the strong EC view lies in the fact that motor system reactivations are action-oriented and prospecting future actions (see Gallagher \& Rucińska, 2021).

Rooted motoric processes, in turn, allow imaginings to justify through perception, because perception re-activates learned patterns of action. Imaginings justify not because they simulate what could be perceived, but because in imagination, we

\footnotetext{
14 As Jones and Schoonen (2018, para. 3) write, "For example, we cannot imagine something being both red and green all over, which might indicate that such a situation is impossible. However, it could equally be a result of our limited embodied perspective. A creature with two visual systems might think otherwise."
} 
re-use the same motoric processes as in perception. These motoric processes, unlike simulations, are habitually informed by perception, which strengthens the justificatory power of imaginings. For example, in imagining how to climb a difficult section of the rock where a hold is not within reach just by stretching one's arm, Alex imagines that he will lean backwards before making a swing and jumping in order to reach the far hold with the tip of his right hand while his left hand presses against the flat surface of the rock. This imagining justifies his choice to perform this rather than another maneuver on the rock, because it is shaped, not by representing a maneuver as possible by simulating what was perceived in the past, but by actively reenacting the movements in imagery that already involve habitually acquired crossmodal motoric and peripheral processes - processes connected to his action-oriented vision, his bodily posture, and tactile sensory stimulation.

Conceptualizing beliefs and perceptions as rooted bodily processes can, in our view, strengthen both Kind and Balcerak Jackson's proposals about the justificatory role of beliefs and perception for imagination. While their arguments for the epistemic role of imagination are justified, they gain more power when beliefs and perceptions that ground these imaginings are seen as strongly embodied, because strong embodiment does not require a representational medium that makes epistemological issues controversial. In the final section, we will discuss the added value of seeing explicitly embodied imaginings as epistemically relevant. However, we will first address one more challenge concerning body schemas.

\subsection{The challenge of perspective-taking}

Even if one accepts, for argument's sake, that rooted embodiment does play a constraining role on imagination, there is a potential problem with the idea that the body schema constrains imagination. If we're always embodied in this sense, how is it possible that we can imagine counterfactual things? And wouldn't our body schemas limit our imagination, in such a way that we can never step away from our perspectives? Clavel-Vázquez and Clavel Vázquez (2018) worry that, while body schemas can constrain imagination, the role of these constraints is overly limiting in this way: one cannot get away from one's own perspective. As they write:

imagining ourselves being someone other [...] is significantly constrained by our own embodiment. This means that we cannot really abandon our perspective to become fully immersed in an imaginative project that would allow us to imagine ourselves being someone other with the relevant affective responses. Our capacity for empathetic imagining is significantly constrained because this exercise of imagination is an embodied exercise of imagination (para. 6).

For example, imagining being someone else who inhabits a perspective different from our own should require that "we imagine ourselves being others who think, feel and respond differently, to circumstances that might be different from our own" (ibid., para. 3). But if we cannot abandon our point of view to adopt a different one, as rooted embodiment would seem to suggest is the case, then embodiment plays a stifling role for our capacities to empathize with others. Strong EC would be seen as 
overly constraining, rather than enabling, imagining new possibilities for action or taking new perspectives.

There are, however, ways to argue against the idea that body schemas are too tightly constricting for imagination. Some authors like Reddy (2003) or Fuchs (2012) propose the opposite view, that body-schematic processes can be seen as enabling the ability to take others' perspective. These authors refer to explicit embodied engagements with other people throughout infancy (second-person interaction, joint attention) that allows for new body schematic processes to develop inclusive of a second person perspective. According to Fuchs (2012), second person perspective is an "intersubjective, participant or co-experiencing perspective, referring to situations of reciprocal interaction that are characterized by some form of mutual relatedness and coupling of the partners" (p. 658). ${ }^{15}$ For Fuchs and others, developmentally, second-person social interaction is prior to first-person, reflective self-consciousness, or anything like theory-of-mind style mindreading. Sharing perspectives in joint attention builds the foundation for understanding and empathizing with others. One's self-perspective, to which Clavel-Vázquez and Clavel Vázquez (2018) refer, is arguably derivative from a more basic embodied and interactive intersubjectivity.

\section{The added value of explicit embodiment to epistemic relevance of imagination}

We now follow up on the reach of strong EC concerning the epistemic relevance of imagination, and discuss examples of cases when explicit motor processes and movement further enhance imagination, including cases that involve pretend play, training, therapy, learning, and practices of marking. In this section, we will begin by arguing for the positive role of overt motor action in pretend play for developing our explicitly embodied imagination, followed by a discussion of the added value of explicitly embodied imagination to the epistemic relevance of imagination.

\subsection{The value of movement for imagining and pretend play}

Motor action in pretend play can make new imaginings possible, and can lead to discovery, as it allows us to see new possibilities for real action. Pretend play provides a myriad of examples of acting 'as if' driven by exploratory action, such as by moving objects. In actively moving objects around and exploring their affordances, we can bring forth new possibilities for pretense, which, in turn allow us to create new meanings (Rucińska, 2017). For example, in intending to act as if a pen is a "rocket", the shape of the pen in the pretender's hand, the limit of her hand's stretch, and her current feelings of either excitement or tiredness can all influence how the "rocket"

\footnotetext{
15 Reference can be made here to Merleau-Ponty's notion of 'intercorporeity', which is a way to characterize primary intersubjective interactions starting in infancy. Such processes carry over in some cases to secondary intersubjective joint actions as recent empirical research on joint body schemas show (Soliman and Glenberg, 2014).
} 
pretense ends up looking. It can start as slow vertical movement in a linear trajectory (representing most accurately how rockets move upon launch), but it can easily be followed by running around with the pen in a horizontal position and making "swoosh" sounds, as well as simply throwing the pen up and down once the actor feels tired. Our embodiment, including our feelings, determine how "rocket play" unfolds and what new shapes it can take. In short, via pretending, we actively move (or don't move) our bodies to bring forth new experiences and new ways of engaging with the world. Pretending, as a form of embodied imagination, can be further guided by other artefacts, props, or people (Rucińska, 2016, 2019). It can lead to a new understanding of physical or social principles, verify a hypothesis, or lead to discovering new possibilities.

As Louis Holtzman (2009) points out, "the unique feature of free play is the creation of an imaginary situation" (p. 50). For example, improvisation players "collectively create imaginative situations", or a Vygostkian zone of proximal development, "going beyond what they know and know how to do" (p. 62). The jointly created zone allows one to explore different behaviors and imagine alternative perspectives. According to Holzman, the action created in the imaginative sphere "frees the players from the situational constraint and at the same time imposes constraints of its own" (p. 51). Vygotsky also views imagination as a feature of collective activity, which makes imagining a social, interpsychological phenomenon. Other people can impose relevant constraints on our imaginings. Corporeal imagination opens the door for the concept of intercorporeal imagination (Stuckenbrock, 2017), where the constraining is done also by the social environment and others within it. We can act with other people, and create environments together that facilitate new imaginings. We can also jointly create our imaginings. Physically moving together can allow us to imagine these new possibilities.

Movement may also assist in respect to social situations that can be difficult for people to imagine, such as imagining how to act to change a toxic relationship with a family member, or in imagining a world where one is not bullied. Sometimes, one cannot even imagine a better life, which is why one might seek therapeutic help. Pretend games, in the context of therapy, allow us to imagine alternative scenarios. In some therapy, you can role-play such situations when you take over the perspective of a person you want to be. When you cannot think it through in your head, you can 'fake it' by acting it out. For instance, in some therapeutic games, parents and children are asked to role-play each other to be able to gain more of a perspective on what's it like for the other person (Rucińska \& Reijmers, 2015). In systemic therapy, the therapists do not simply give us new perspectives to re-enact or impose how the role should be played; the therapist helps us discover, through playing various roles together, what other perspectives are available to us. For example, to help us imagine what it is like to be assertive, we can act it out in pretend play, and discover through role-play that different ways of responding to a stressful situation are possible. This not only allows us to individually learn something new about ourselves, but allows us to understand each other better, and find new, shared ways of communicating.

The various examples we've cited here and in Sect. 3 can be described as examples of imaginative pretense: marking involved in rock climbing is a form of pretending to climb; therapy involves role-playing; in the self-defense class we pretend 
there is an attacker. These forms of explicitly embodied actions can play a beneficial role for our capacity to imagine. These cases show that sometimes, it is pretending that can lead to further imagining possibilities for action. Imaginative capacities can sometimes be gained with movement, and not just be used in movement. ${ }^{16}$

\subsection{The epistemic value of explicitly embodied imagination}

Earlier we discussed some examples of marking and pretense where explicit bodily movement or performance played a crucial role in bringing forth new imaginative experiences. These cases show that one can learn something new from imagination that involves explicit movement, which shows the added value of acknowledging explicitly embodied imagination in the discussion on the epistemic relevance of imagination.

One of the added values of movement is that it allows us to imagine situations that are difficult to imagine, and from which we can learn, contra Sartre and Wittgenstein. These are situations that have to do with learning new concepts, like struggling to imagine how a mathematical equation adds up, or struggling to imagine the movement of planets or the principles of gravity (Gallagher \& Lindgren, 2015). Physical action can make a difference in this regard. Movement can infuse our imaginings. The action involved can be a kind of play-acting or pretense. Plummer (2009) showed that acting out celestial trajectories in one's own bodily movement has learning gains. Some children (and adults) may find it hard to imagine what it means that an asteroid "conserves length", but in their own full-body performance, they succeeded in imagining how objects move through space. In acting out the behavior of an asteroid, the actor makes a better prediction about its trajectory, gaining a better grasp of the physical laws he or she is trying to learn about. Imagining in these contexts relies on moving one's whole body (e.g., running, jumping); and movement can be leveraged to create learning situations based on kinaesthetic conflict (Gallagher \& Lindgren, 2015). These empirical studies demonstrate improved learning in science, math and other subjects, compared to using minimal body movement (hand and mouse) to control the same movements on the computer screen. Likewise, Thompson and Goldstein (2020), in a study of imaginative role-playing, suggest:

Role play embodiment involves taking on the identity of a character and performing actions that are related to that identity. This embodiment of characters actively, physically, and affectively engages children, allowing them to be full participants in the pretense scenario and potentially having consequences for children's learning from such scenarios (ibid., p. 1366).

Hence, performance has an added value to learning in part because of the physical and active dimension that movement brings.

\footnotetext{
16 This is the position of Picciuto and Carruthers (2016) who speak of pretense as a "kind of embodied imagination", but by that they mean that pretense takes place only when imagination actively guides one's movements (p. 317). For arguments about why pretending doesn't always need imagining, see Langland-Hassan (2015) and Mitchell (2016).
} 
However, another important aspect of what allows performance, action, and movement to make a difference is the additional affective dimension that movement brings. I can't really imagine what's it like to be a superstar who won the Idol or $X$ Factor. But I can try to imagine it by pretending to give an award-winning performance during a karaoke session, and getting feelings of anxiety when listened to and judged by strangers. Similarly, I can't possibly imagine the hardships of being a migrant by sitting in my comfortable apartment and watching a documentary. But by participating in "The Night of the Refugee" event (Nacht van de Vluchteling ${ }^{17}$ ), I may be a step closer to being able to imagine, even if incompletely or just for a second, what it could be like to be a migrant walking from city to city in the middle of the night, or when confronted by a long and arbitrary selection procedure when trying to enter a ferry to continue my walk (see the 'Extraordinary Cueing Experience' project). ${ }^{18}$ What was completely unimaginable to me before, now becomes less unimaginable; and, while clearly, the organized experience cannot replace a true experience, the organizers of the event (a group of actors and artists from Syria, Italy, Iran, Switzerland, Afghanistan and the Netherlands, some of who are former migrants) aimed to "let the audience feel a hint of some of the experiences" (van Houte 2017, para. 3) they had on their journeys. The explicitly enacted imagining can teach us just how much one cannot really fathom about real migrant struggles that include long-lasting feelings of fear for safety and one's life, or feelings of hunger. Discovering how one feels through such imaginative actions allows one to also learn something about oneself: one's limitations, likes and dislikes, propensities for future actions, and even the limits of own imagination. It may also allow for the opening up of new possibilities for later imaginings. ${ }^{19}$

\section{Conclusion}

In this paper we have shown that imagining can be both augmented and constrained by motoric processes rooted in bodily, body-schematic and affective processes, as well as by explicit motor actions. We proposed that the perspective of strong EC can aid the arguments of Kind and Balcerak Jackson on the justificatory role of imagination, because our model of imagination explains how it is that we reuse the perceptual motor system involved in the experienced action, and in the act of prospecting future actions. Insights based on this strong sense of embodiment have been missing from the discussion of the constraints and epistemic relevance of imagination.

We've suggested that processes involved in rooted embodiment can enhance arguments about the epistemic role of beliefs and desires (Kind) and perceptions

\footnotetext{
17 "The Night of the Refugee" is a non-profit charity event intended to raise awareness and money in support of migrants coming to Europe. For more about this event, see: https://www.nachtvandevluchteling.nl/over-de-nacht-van-de-vluchteling.

18 To read more about the 'Extraordinary Cueing Experience' at the Night of the Refugee, see van Houte (2017): http://www.contained-project.com/the-extraordinary-queuing-experience-at-the-night-of-therefugee/.

19 Thanks to Martin Weichold for this insight.
} 
(Balcerak Jackson) in constraining imagination, because processes involved in rooted embodiment permeate these cognitive processes as well. Rooted embodiment contributes to the justificatory power of imagination, as it can make imagination more accurate and reliable, even though it does not guarantee truth. In case of belief, it is not 'body as content' but the actual body-schematic motor capabilities that guide beliefs and imaginings. Drawing on actual motoric habits and skills justifies the idea that imagining can be close to real experiences, without having to involve a strong will to imagine correctly. In the case of perception, on our view, perceptual simulations of possibilities for action represented 'as possible' are not needed, as perception re-activates learned patterns of action.

There is also the added value for strongly embodied imagination connected with processes of explicit embodiment. We have shown that imaginings may be closely coupled to the dynamic constraints involved in interacting in the world just so far as bodily movement and action are constrained by how we relate to our environment and engage with others. When we imagine with movement, we can't imagine anything we want, as our movements are constrained not just by the actual parameters of the body and developed body schema, but by ongoing environmental situations, including those involving other people. The examples of marking during rock climbing and self-defense training, both performed in interactive contexts, showed that engaging with other people can play an additional role in constraining our imaginings, something not mentioned or emphasized by other theories of embodied imaginings. ${ }^{20}$ We thus argued that explicit bodily processes play a role in our imagination, and that imagination can be seen as an embodied doing. Strongly embodied imagining means that the imagining is never 'detached' from the body, or the environment in which we do the imagining, but this does not make them any less imaginings. ${ }^{21}$ Explicit motor processes and movement can further enhance imagination, as we see new possibilities for action and learn from our new experiences, making 'the unimaginable' imaginable.

But does training and learning make us better imaginers, and therefore, expand the justificatory role of imagination $?^{22}$ We believe that the answer to this question is 'yes'. Training and learning contexts that involve explicit bodily performances can open new possibilities for imagining, in which we can enact our imaginings to gain new insights and 'test' whether or not what we imagine matches reality, and is thus justified. However, there are also potential limitations of our view. First, explicitly embodied imaginings of future states or possibilities do not replace true experiences; even the best simulation during an embodied performance does not provide the same experiences as going through the real experiences when one is not imagining

\footnotetext{
${ }^{20}$ Picciuto and Carruthers (2016, p. 323), for example, say that the added value of explicit embodiment is that it helps one maintain one's focus on and intensity of one's imagining. This is a much more limited role of explicit embodiment than what we have offered.

21 As Kind argues, "the introduction of constraints - even substantive constraints - in our mental processes should not be seen to suggest that these mental processes no longer count as imaginings" (2018, p. 243). Kind references beliefs and desires, while we extend this idea to environmental and social constraints.

22 Thanks to the anonymous reviewer for this question.
} 
any more. ${ }^{23}$ Also, our model still needs to account for how it is that imaginative confabulations are possible, without involving misrepresentations. These considerations require more work and should be reserved for future analyses. Although we have not answered all the problems associated with the justificatory power of imagination, we did highlight that 'going strongly embodied' does offer additional insight to the kinds of arguments proposed by Kind and Balcerak Jackson.

Acknowledgements This work was made possible thanks to the FWO grant "Enactive Approach to Pretending" [12J0419N]. We would like to thank Martin Weichold and three anonymous reviewers for their comments on the earlier version of this paper.

Open Access This article is licensed under a Creative Commons Attribution 4.0 International License, which permits use, sharing, adaptation, distribution and reproduction in any medium or format, as long as you give appropriate credit to the original author(s) and the source, provide a link to the Creative Commons licence, and indicate if changes were made. The images or other third party material in this article are included in the article's Creative Commons licence, unless indicated otherwise in a credit line to the material. If material is not included in the article's Creative Commons licence and your intended use is not permitted by statutory regulation or exceeds the permitted use, you will need to obtain permission directly from the copyright holder. To view a copy of this licence, visit http://creativecommons.org/licen ses/by/4.0/.

\section{References}

Alsmith, A. J. T., \& de Vignemont, F. (2012). Embodying the mind and representing the body. Review of Philosophy and Psychology, 3, 1-13

Balcerak Jackson, M. (2018). Justification by imagination. In F. Macpherson \& F. Dorsch (Eds.), Perceptual imagination and perceptual memory.Oxford University Press.

Clark, A. (1999). An embodied cognitive science? Trends in Cognitive Sciences, 3(9), 345-351.

Clark, A. (2008). Supersizing the mind: Embodiment, action, and cognitive extension. New York: Oxford University Press.

Clark, A., \& Grush, R. (1999). Towards a cognitive robotics. Adaptive Behavior, 7(1), 5-16

Clavel-Vázquez, A., \& Clavel Vázquez, M .J. (2018, August 8). Embodied imagination: Why we can’t just walk in someone else's shoes. The Junkyard: A scholarly blog devoted to the study of imagination (Ed. A. Kind). https://junkyardofthemind.com/blog/2018/8/5/embodied-imagination-why-we-cantjustwalk-in-someone-elses-shoes.

Colombetti, G. (2014). The feeling body: Affective science meets the enactive mind. MIT Press.

Currie, G., \& Ravenscroft, I. (2002). Recreative minds: Imagination in philosophy and psychology. Oxford University Press.

De Jaegher, H., Di Paolo, E., \& Gallagher, S. (2010). Can social interaction constitute social cognition? Trends in Cognitive Sciences, 14(10), 441-447.

de Vignemont, F. (2010). Body schema and body image-Pros and cons. Neuropsychologia, 48(3), $669-680$.

Di Paolo, E. (2009). Extended life. Topoi, 28, 9-21

Di Paolo, E., \& Thompson, E. (2014). The enactive approach. In L. Shapiro (Ed.), The Routledge handbook of embodied cognition (pp. 68-78). New York: Routledge Press.

Fuchs, T. (2012). The phenomenology and development of social perspectives. Phenomenology and the Cognitive Sciences, 12, 655-683

\footnotetext{
23 This is an interesting worry that has relevance for questions about empathy as well (see Zahavi, 2014, p. 113).
} 
Gallagher, S. (2005a). Dynamic models of body schematic processes. In H. De Preester \& V. Knockaert (Eds.), Body image and body schema: Interdisciplinary perspectives on the body. (pp. 233-250). John Benjamins.

Gallagher, S. (2005b). How the body shapes the mind. Oxford University Press.

Gallagher, S. (2008). Are minimal representations still representations? International Journal of Philosophical Studies, 16(3), 351-369

Gallagher, S. (2015). Reuse and body-formatted representations in simulation theory. Cognitive Systems Research, 34-35, 35-43. https://doi.org/10.1016/j.cogsys.2015.07.003

Gallagher, S. (2017). Enactivist interventions: Rethinking the mind. Oxford University Press.

Gallagher, S. (2020). Action and interaction. Oxford University Press.

Gallagher, S. (2021). Performancelart: The venetian lectures. Mimesis Mimesis International Edizioni.

Gallagher, S., \& Bower, M. (2014). Making enactivism even more embodied. AVANT/Trends in Interdisciplinary Studies, 5(2), 232-247

Gallagher, S., \& Cole, J. (1995). Body schema and body image in a deafferented subject. Journal of Mind \& Behavior, 16(4), 369-390.

Gallagher, S., \& Lindgren, R. (2015). Enactive metaphors: Learning through full-body engagement. Educational Psychology Review, 27(3), 391-404

Gallagher, S., \& Rucińska, Z. (2021). Prospecting performance: Rehearsal and the nature of imagination. Synthese. https://doi.org/10.1007/s11229-020-02989-2

Gallese, V. (2010). Embodied simulation and its role in intersubjectivity. In T. Fuchs, H. C. Sattel, \& P. Henningsen (Eds.), The embodied self: Dimensions, coherence and disorders (pp. 78-92). Stuttgart: Schattauer.

Gendler, T. (2010). Intuition, imagination, and philosophical methodology. Oxford University Press.

Gendler, T. S. (2000). The puzzle of imaginative resistance. The Journal of Philosophy, 97(2), 55-81

Goldman, A. (2012). A moderate approach to embodied cognitive science. Review of Philosophy and Psychology, 3(1), 71-88.

Goldman, A. I. (2006). Simulating minds: The philosophy, psychology, and neuroscience of mindreading. Oxford University Press.

Goldman, A., \& de Vignemont, F. (2009). Is social cognition embodied? Trends in Cognitive Sciences, 13(4), 154-159.

Grandin, T. (1995). Thinking in pictures. Random House.

Hochstetter, G. (2016). Attention in bodily awareness. Synthese, 193(12), 3819-3842.

Holtzman, L. (2009). Vygotsky at work and play. Routledge.

Hutto, D. D. (2010). Radical enactivism and narrative practice: Implications for psychopathology. In T. Fuchs, P. Henningsen, \& H. C. Sattel (Eds.), Coherence and disorders of the embodied self. (pp. 43-66). Schattauer.

Hutto, D. D. (2015). Overly enactive imagination? Radically re-imagining imagining. The Southern Journal of Philosophy, 53, 68-89

Hutto, D. D., \& Myin, E. (2013). Radicalizing enactivism: Basic minds without content. Cambridge, MA: MIT Press.

Ilundáin-Agurruza, J. (2017). Muscular imaginings-A phenomenological and enactive model for imagination. Sport, Ethics and Philosophy, 11(1), 92-108

Johnson, M. (1987). The body in the mind: The bodily basis of meaning, imagination, and reason. University of Chicago Press.

Jones, M., \& Schoonen, T. (2018, August 22). Embodied constraints on imagination. The Junkyard: A scholarly blog devoted to the study of imagination (Ed. A. Kind). https://junkyardofthemind.com/ blog/2018/8/19/embodied-constraints-on-imagination.

Kim, J. H. (2020). From the body image to the body schema, from the proximal to the distal: Embodied musical activity toward learning instrumental musical skills. Frontiers in Psychology, 11, 101

Kind, A. (2016). Imagining under constraints. In A. Kind \& P. Kung (Eds.), Knowledge through imagination. (pp. 145-159). Oxford University Press.

Kind, A. (2018). How imagination gives rise to knowledge. In F. Macpherson \& F. Dorsch (Eds.), Perceptual imagination and perceptual memory. (pp. 145-159). Oxford University Press.

Kyselo, M., \& Di Paolo, E. (2015). Locked-in syndrome: A challenge for embodied cognitive science. Phenomenology and the Cognitive Sciences, 14(3), 517-542

Lakoff, G., \& Johnson, M. (1980). Metaphors we live by. University of Chicago Press.

Lakoff, G., \& Johnson, M. (1999). Philosophy in the flesh: The embodied mind and its challenge to Western thought. New York: Basic Books. 
Langland-Hassan, P. (2015). Imaginative attitudes. Philosophy and Phenomenological Research, 90(3), $664-687$

Langland-Hassan, P. (2020). Explaining imagination. Oxford University Press.

Longo, M. R., \& Haggard, P. (2010). An implicit body representation underlying human position sense. Proceedings of the National Academy of Sciences, 107(26), 11727-11732.

Medina, J. (2013). An enactivist approach to the imagination: Embodied enactments and "fictional emotions." American Philosophical Quarterly, 50(3), 317-335

Mitchell, R. W. (2016). Can animals imagine? In A. Kind (Ed.), Routledge handbook of philosophy of imagination. (pp. 326-339). Routledge.

Noë, A. (2004). Action in perception. MIT press.

Núñez, R. (2010). Enacting infinity: Bringing transfinite cardinals into being. In J. Stewart, O. Gappene, \& E. Di Paolo (Eds.), Enaction: Towards a new paradigm in cognitive science (pp. 307-33). Cambridge, MA: MIT Press.

O'Regan, K., \& Noë, A. (2001). A sensorimotor account of vision and visual consciousness. Behavioral and Brain Sciences, 24, 939-1031

Petracca, E. (2020). Two and a half systems: The sensory-motor system in dual-process judgment and decision-making. Journal of Neuroscience, Psychology, and Economics, 13(1), 1-18

Picciuto, E., \& Carruthers, P. (2016). Imagination and pretense. In A. Kind (Ed.), The Routledge handbook of philosophy of imagination. (pp. 334-345). Routledge.

Plummer, J. D. (2009). Early elementary students' development of astronomy concepts in the planetarium. Journal of Research in Science Teaching, 46(2), 192-209

Reddy, V. (2003). On being the object of attention: Implications for self-other consciousness. Trends in Cognitive Sciences, 7(9), 397-402

Rowlands, M. (2006). Body language. Cambridge, MA: MIT Press.

Rucińska, Z. (2016). What guides pretence? Towards the interactive and the narrative approaches. Phenomenology and the Cognitive Sciences, 15, 117-133. https://doi.org/10.1007/s11097-014-9381-Z

Rucińska, Z. (2017). The role of affordances in pretend play. In C. Durt, T. Fuchs, \& C. Tewes (Eds.), Embodiment, enaction, and culture: Investigating the constitution of the shared world (pp. 257277). MIT Press. https://doi.org/10.7551/mitpress/9780262035552.003.0015.

Rucińska, Z. (2019). Social and enactive perspectives on pretending. Avant. https://doi.org/10.26913/ avant.2019.03.15

Rucińska, Z. (2021). Enactive planning in rock climbing: Recalibration, visualization and nested affordances. Synthese. https://doi.org/10.1007/s11229-021-03025-7

Rucińska, Z., \& Reijmers, E. (2015). Enactive account of pretend play and its application to therapy. Frontiers in Psychology, 6, 175. https://doi.org/10.3389/fpsyg.2015.00175

Sanchez-Garcia, R., Fele, G., \& Liberman, K. (2019). Ethnomethodological respectifications of cognition in sport. In M. L. Cappuccio (Ed.), Handbook of embodied cognition and sport psychology (pp. 511-534). Cambridge, MA: The MIT Press.

Sartre, J. (1972). The psychology of the imagination. London: Methuen.

Shapiro, L. (2011). Embodied cognition. Routledge Press.

Silverman, D. (2017). Bodily skill and internal representation in sensorimotor perception. Phenomenology and the Cognitive Sciences, 17(1), 157-173

Soliman, T., \& Glenberg, A. M. (2014). The embodiment of culture. In L. Shapiro (Ed.), The Routledge handbook of embodied cognition. (pp. 207-219). Routledge/Taylor \& Francis Group.

Stukenbrock, A. (2017). Intercorporeal phantasms: Kinesthetic alignment with imagined bodies in selfdefense training. In C. Meyer, J. Streeck, \& S. Jordan (Eds.), Intercorporeality. Emerging socialities in interaction. (pp. 237-263). Oxford University Press.

Thompson, B. N., \& Goldstein, T. R. (2020). Children learn from both embodied and passive pretense: A replication and extension. Child Development, 91(4), 1364-1374

Thompson, E., \& Cosmelli, D. (2011). Brain in a Vat or Body in a World? Brainbound versus Enactive Views of Experience. Philosophical Topics, 39(1), 163-180.

Thompson, E., \& Varela, F. (2001). Radical embodiment: Neural dynamics and consciousness. Trends in Cognitive Sciences, 5, 418-25.

van Houte, M. (2017, June 17). The extraordinary queuing experience at the night of the refugee. Contained Project. http://www.contained-project.com/the-extraordinary-queuing-experience-at-thenight-of-the-refugee/.

Van Leeuwen, N. (2011). Imagination is where the action is. The Journal of Philosophy, 108(2), 55-77

Wheeler, M. (2005). Reconstructing the cognitive world: The next step. MIT Press. 
Wheeler, M. (2010). In defense of extended functionalism. In R. Menary (Ed.), The extended mind. Cambridge, MA: MIT Press.

Wilson, R. A. (2004). Boundaries of the mind: The individual in the fragile sciences - Cognition. Cambridge: Cambridge University Press.

Wittgenstein, L. (1981). Zettel. Trans G. E. M. Anscombe, 2nd edn. Oxford: Basil Blackwell.

Yablo, S. (1993). Is conceivability a guide to possibility? Philosophy and Phenomenological Research, 53(1), 1-42

Zahavi, D. (2014). Self and other: Exploring subjectivity, empathy, and shame. Oxford University Press.

Publisher's Note Springer Nature remains neutral with regard to jurisdictional claims in published maps and institutional affiliations. 